\title{
Exercise combined with a probiotics treatment alters the microbiome, but moderately affects signalling pathways in the liver of male APP/PS1 transgenic mice
}

\author{
Tímea Téglás · Dóra Ábrahám · Mátyás Jókai · Saki Kondo · Rezieh Mohammadi • \\ János Fehér · Dóra Szabó • Marta Wilhelm • Zsolt Radák (i)
}

Received: 19 May 2020/ Accepted: 7 August 2020/Published online: 18 August 2020

(C) The Author(s) 2020

\begin{abstract}
It has been demonstrated that physical exercise and probiotic supplementation delay the progress of Alzheimer's Disease (AD) in male APP/ $\mathrm{PS}^{\mathrm{TG}}$ mice. However, it has also been suggested that both exercise and AD have systemic effects. We have studied the effects of exercise training and probiotic treatment on microbiome and biochemical signalling proteins in the liver. The results suggest that liver is under oxidative stress, since SOD2 levels of APP/PS1 mice were decreased when compared to a wild type of mice. Exercise training prevented this decrease. We did not find significant changes in COX4, SIRT3, PGC-1a or GLUT4 levels, while the changes in pAMPK/AMPK, pmTOR/mTOR, pS6/S6 and NRF2 levels were randomly modulated. The data suggest that exercise and probiotics-induced changes in
\end{abstract}

T. Téglás · D. Ábrahám · M. Jókai ·

S. Kondo · R. Mohammadi · Z. Radák $(\bowtie)$

Research Center for Molecular Exercise Science,

University of Physical Education, Alkotas str. 44,

Budapest 1123, Hungary

e-mail:radak@tf.hu

S. Kondo

Department of Life Sciences, Graduate School of Arts and

Sciences, The University of Tokyo, Tokyo 113-8654,

Japan

\section{J. Fehér}

Ophthalmology Unit, NESMOS Department, Sant'Andrea

Hospital, Faculty of Medicine and Psychology,

"Sapienza" University of Rome, Rome, Italy microbiome do not strongly affect mitochondrial density or protein synthesis-related AMPK/mTOR/ S6 pathways in the liver of these animals.

Keywords Alzheimer's disease - Microbiome . Liver $\cdot$ Probiotics $\cdot$ Exercise $\cdot$ Metabolism

$\begin{array}{ll}\text { Abbreviations } \\ \text { AD } & \text { Alzheimer's disease } \\ \text { BSA } & \text { Bovine serum albumin } \\ \text { HRP } & \text { Horseradish peroxidase } \\ \text { mo. } & \text { Months } \\ \text { p-S6 } & \text { Phosphor-ribosomal protein } \\ \text { PVDF } & \text { Polyvinylidene fluoride } \\ \text { rpS6 } & \text { Ribosomal protein } \\ \text { RT } & \text { Room temperature }\end{array}$

D. Szabó

Semmelweis University, Budapest, Hungary

M. Wilhelm · Z. Radák

Institute of Sport Sciences and Physical Education,

Faculty of Science, University of Pécs, Pecs 2020,

Hungary

M. Wilhelm · Z. Radák

Faculty of Sport Sciences, Waseda University,

Saitama 359-1192, Japan 
S6

Ribosomal protein

SDS-

Sodium dodecyl sulphate-

PAGE

polyacrylamide gel electrophoresis

TBS-T

\section{Introduction}

The microbiome of the human gastrointestinal tract is the largest reservoir of microbes in the human body. The bacterial density of the human gut is the highest in any known microbial ecosystem (Kim et al. 2013; Hill et al. 2014). The microbiota of the gut is crucial to the breakdown of dietary nutrients, regulation of intestinal and systemic immune responses, and production of small molecules critical for intestinal metabolism, as well as the generation of several gases that can modulate cellular function (Singhal and Shah 2020). Due to the complex function of the gut microbiome, the diversity of microbes is defined by the number and abundance of the distribution of distinct types of organisms (Huttenhower et al. 2012).

The microbiota-gut-brain axis is the most popular hypothesis, which includes a bidirectional communication system, that is connected via neural, immune, endocrine, and metabolic pathways (Cryan and O'Mahony 2011; Collins et al. 2012; Szablewski 2018). Accumulated evidence also supports a possible connection between the gut microbiota and neurodegenerative disorders (Bell et al. 2019), including dementia and Alzheimer's Disease (AD) in humans (Xu and Wang 2016; Hu et al. 2016) and in rodents (Zhang et al. 2017; Bäuerl et al. 2018). The changes in the microbiome are linked to defects in synaptogenesis, and cognitive impairment, including AD (Aziz et al. 2013; Brenner 2013; Saulnier et al. 2013; Hornig 2013; Mitew et al. 2013).

$\mathrm{AD}$ is a complex age-related disorder, characterized by a progressive cognitive decline. A limited number of studies have attempted to address the role of gut microbiota in AD. The colonization and modulation of gut microbiota impact brain development and subsequently, adult behaviour (Heijtz et al. 2011; Mancuso and Santangelo 2018) and this connection will probably aid in AD prevention and treatment (Hu et al. 2016). In humans, Vogt et al. (2017) have described previously the correlation between levels of differentially abundant genera and cerebrospinal fluid (CSF) biomarkers of AD.

Recently, we have shown that probiotic supplementation alone, or with exercise training, or exercise training alone, significantly changes the composition of the microbiome and reduces the levels of amyloid beta in the brain of APP/PS1 transgenic mice (Abraham et al. 2019). It is known that probiotic supplementation also beneficially affects liver in patients suffering from non-alcoholic fatty liver diseases (Liu et al. 2019).

It has been shown that animals having APP/PS1 genetic manipulation demonstrate impaired metabolism in kidney, liver, spleen, and thymus (GonzálezDomínguez et al. 2015a). Indeed, it appears that AD is a systemic disease (González-Domínguez et al. 2015b; Wang et al. 2017). Regular exercise also has systemic effects (Radak et al. 2008), which include powerful beneficial effects on liver (Ghiasi et al. 2019; Aamann et al. 2019; Sato et al. 2019; Zhang et al. 2020). Moreover, evidence suggests that exercise reduces the incidence of AD (Radak et al. 2010; Abe 2012). It has further been shown that short-term physical exercise enhances neurogenesis in the amyloid beta-induced AD model (Kim et al. 2014). Voluntary exercise can decrease amyloid load in theTgCRND8 transgenic mice model (Adlard 2005). Due to the systemic effects of exercise, a number of research studies have found that exercise alters the microbiome of the gut (Allen et al. 2018; Sohail et al. 2019; Grosicki et al. 2019; Mahizir et al. 2020; Gubert et al. 2020; Greenhill 2020).

It is important to know whether exercise and probiotic treatment-induced changes in the microbiome could cause alterations in liver metabolism, mitochondrial content, or protein synthesis. Therefore, we have investigated the effects of physical exercise and probiotic treatment on liver metabolism and the pathophysiology of APP/PS1 transgenic mice, by assessing nuclear factor erythroid 2-related factor 2 (NRF-2), 5' AMP-activated protein kinase (AMPK), and mammalian target of rapamycin- (mTOR), associated pathways.

\section{Materials and methods}

Experimental animals

Twenty-four (24), 3-month old, male APP/PS1 transgenic mice (B6C3-Tg (APPswe, PSEN1dE9) 85Dbo/ 
Mmjax; APP/PS1 ${ }^{\mathrm{TG}}$ ) and six (6) wild type controls were used in this study. We have previously demonstrated that cognitive performance is decreased in the Morris water maze and Y-maze tests in APP/PS1 $1^{\mathrm{TG}}$ mice (Abraham et al. 2019). Rodents were randomly divided into control (APP/PS1 $1^{\text {TG }}$ - $)$ ), exercised (APP/ $\left.\mathrm{PS}_{1}{ }^{\mathrm{TG}}-\mathrm{E}\right)$, probiotic treated (APP/PS1 $\left.{ }^{\mathrm{TG}}-\mathrm{P}\right)$, and combined (exercise and probiotic treatment, APP/ $P S 1^{\mathrm{TG}}$-E-P) groups ( $\mathrm{n}=6$, in each group). The wild type animals were from the same colony and were used as the absolute control group $(\mathrm{Wt})(\mathrm{n}=6)$. All experimental procedures, which were carried out on the animals, had been approved by the Semmelweis University Ethics Committee (No: PEI/2015-6/2014).

\section{Experimental design}

The experimental groups (E, E-P) were subjected to exercise of interval running on a rodent treadmill for 20 weeks, with the aim of decreasing the progress of AD development and functional impairment. Training was performed four times per week, for $60 \mathrm{~min}$. The training sessions lasted ten cycles, each cycle consisting of four minutes at high intensity $(20 \mathrm{~m} / \mathrm{min})$ and two minutes low intensity $(10 \mathrm{~m} / \mathrm{min})$. Animals from the control, probiotic treated, and the wild type control groups were placed on the treadmill for the same time period as the trained animals, without receiving any exercise training.

The probiotic treated mice were supplemented by Framelin, which contains probiotics Bifidobacterium longum and Lactobacillus acidophilus lysates, vitamins A and D, and omega 3 fatty acids in cod liver oil, as well as vitamins B1, B3, B6, B9, B12. The supplementation of Framelin was carried out five times per week (120 mg/day) for 20 weeks, along with rodent chow. We monitored daily the food uptake of all mice and found that probiotic treatment did not alter the amount of food and water intake of the animals.

After the 20 week treatment period, animals were anesthetized with one dose $(0.1 \mathrm{ml} / 10 \mathrm{~g}$ bw) of ketamine via intraperitoneal injection (Richter, $100 \mathrm{mg} / \mathrm{ml}$ ), and a xylazine (Produlab Pharma, $20 \mathrm{mg} / \mathrm{ml}$ ) cocktail, and transcardially perfused with heparinized, ice-cold physiological saline. The liver was quickly removed and placed on a frozen icedcooled glass plate. Fecal samples were collected for microbiome analyses the day before the end of the experiment. The samples were stored at $-80{ }^{\circ} \mathrm{C}$ until processing.

$$
\text { 14073936-3729-4475-8958-1ad1cf3f27f0 }
$$

Western blot analysis

The liver of each animal was homogenized in ice and lysed in a lysis buffer containing $137 \mathrm{mM} \mathrm{NaCl}$, $20 \mathrm{mM}$ Tris- $\mathrm{HCl} \mathrm{pH} 8.0,1 \%$ Nonidet P-40, $10 \%$ glycerol, and tablets of protease and phosphatase inhibitors. Lysates were centrifuged for $15 \mathrm{~min}$ at $14.000 \mathrm{~g}$ at $4{ }^{\circ} \mathrm{C}$. Protein concentration was measured using the Bradford assay (Bradford 1976). Proteins were separated on $8-15 \%$ (v/v) SDS-PAGE (sodium dodecyl sulphate-polyacrylamide) gels at room temperature (RT) and transferred onto PVDF membrane (pore size: 0.2 and $0.4 \mu \mathrm{m}$ ) at $4{ }^{\circ} \mathrm{C}$. The nonspecific binding of immune-proteins was blocked with $5 \%$ BSA (bovine serum albumin) dissolved in Trisbuffered saline Tween 20 (TBS-T) for $1 \mathrm{~h}$ (h) at RT. After blocking, the membranes were incubated with primary GAPDH (mouse, 1:40,000; Sigma-Aldrich), SIRT1 mouse (1:1000, Abcam), SIRT3 rabbit (1:10,000, ProteinTech), rabbit GLUT4 (1:500, Santa Cruz), rabbit SOD2 (1:3000, Invitrogen), goat COX4 (1:2000, Abcam), rabbit PGC1-alpha (1:5000, Novus Biologicals), rabbit S6 Ribosomal Protein (1:5000, Cell Signaling), rabbit Phospho-S6 Ribosomal Protein (1:5000, Ser235/236, Cell Signaling), rabbit AMPK (1:25,000, Cell Signaling), rabbit pAMPK (1:1500, Cell Signaling), rabbit AKT (1:3000, Cell Signaling, rabbit pAKT (1:2000, Cell Signaling), rabbit pmTOR (1:1500, Cell Signaling), rabbit mTOR (1:1000, Cell Signaling) or rabbit NRF-2 (1:1000, Abcam) antibodies in TBS-T containing 5\% BSA, overnight at $4{ }^{\circ} \mathrm{C}$. After overnight incubation the membranes were rinsed in TBS-T attended by one hour of incubation with HRP-conjugated secondary antibodies at RT. The secondary antibodies were: anti-rabbit, anti-mouse and anti-goat IgG in TBS-T containing 1\% BSA (1:10,000; Jackson Immunoresearch). Between incubation times, the membranes were washed repeatedly $(3 \times 10 \mathrm{~min})$ and after the last washing session, incubated with an enhanced chemiluminescent reagent (ECL Star Enhanced Chemiluminescent Substrate; Euroclone) for one minute. The protein bands were visualized on X-ray film. Bands were quantified by Image 1.52 software, and total protein normalization was used for the analysis. 


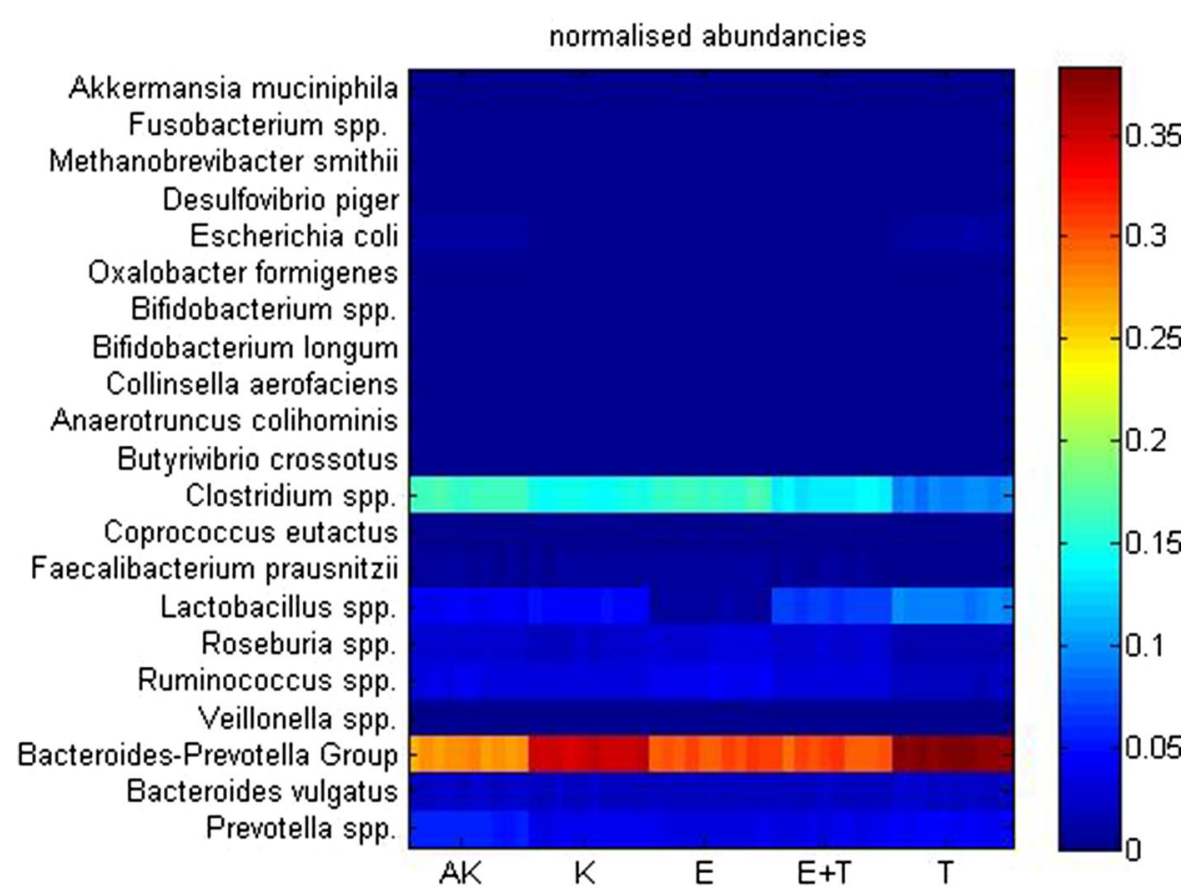

Fig. 1 The effects of exercise and probiotic treatments on the gut microbiome of wild and APP/PS1 transgenic mice. The figure shows the bacterial content of wild type (Wt), (APP/

\section{Microbiome analysis}

Microbiome was analyzed by $16 \mathrm{~S}$ ribosomal rDNA amplicon sequencing and bioinformatics as described previously (Abraham et al. 2019).

\section{Statistical analyses}

The Statistica 13.2 program was used for all statistical analyses. The Shapiro-Wilk W-test was used to determine normality. For the parametric variables, three-way ANOVA was used (with the three- degree factorial), followed by the Tukey's post hoc test. The correlation between two variables was measured using the Pearson coefficient. Statistical significance was established at $\mathrm{P}<0.05$. Means \pm SEMs are shown in the figures.

\section{Results}

The effects of exercise and probiotics treatment on liver

Figure 1 shows the differences in microbiome concentration of wild, and transgenic control, exercise
$\left.\mathrm{PS} 1^{\mathrm{TG}}-\mathrm{C}\right)$, exercise trained (APP/PS1 $\left.{ }^{\mathrm{TG}}-\mathrm{E}\right)$, probiotic treated (APP/PS1 ${ }^{\text {TG }}-\mathrm{P}$ ), and combined (exercise trained and probiotic treatment, APP/PS $1^{\text {TG }}$-E-P) groups $(n=6)$

trained, as well as probiotic treated mice. It is clear from these data that the microbiome of APP/PS1 ${ }^{\mathrm{TG}}$ mice is very different from the wild type, as the effects of both interventions alone or in combination significantly altered the bacterial flora of the microbiome. As we reported earlier, the changes in the bacterium flora in the gut microbiome are associated with brain function and accumulation of amyloid beta proteins (Abraham et al. 2019).

In the fecal microbiome Firmicutes and Bacteroidetes are the most abundant prokaryotic species. Our results revealed that the ratio of the Firmicutes/ Bacteroides was the lowest in the APP/SP1-P group and the highest in the Wt group without APP/PS1 overexpression. Indeed, in the Wt control group we found a decreased ratio of Firmicutes to Bacteroides species, compared to the APP/PS1 groups. The level of L. johnsonii positively correlated with beta amyloid content and area $(\mathrm{p}<0.05)$ in the hippocampus (Abraham et al. 2019). However, a significant relationship was not detected between the level of bacterial species in the microbiome and the measured protein levels in the liver. Therefore, it is suggested that the impact of these interventions on the liver 

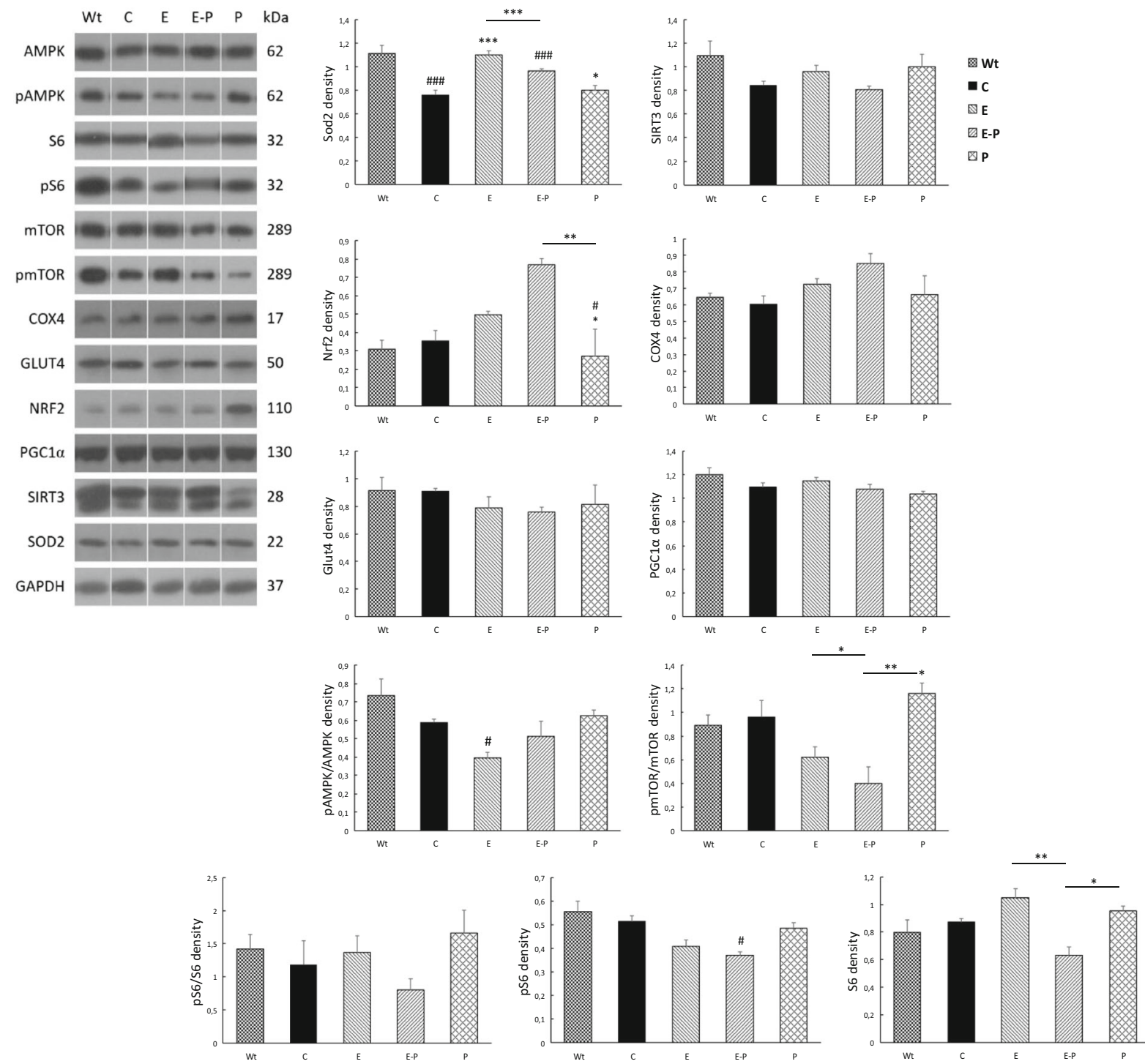

Fig. 2 The effects of exercise and probiotic treatments on selected protein contents. Exercise and probiotic treatments randomly altered the selected protein concentrations in the livers of wild and transgenic animals. Wild type (Wt), control (APP/ $\left.\mathrm{PS} 1^{\mathrm{TG}}-\mathrm{C}\right)$, exercise trained (APP/PS1 $\left.{ }^{\mathrm{TG}}-\mathrm{E}\right)$, probiotic treated (APP/PS1 $\left.{ }^{\mathrm{TG}}-\mathrm{P}\right)$, and combined (exercise trained and probiotic

appears to be less pronounced than found in the brain. Exercise training of probiotic supplementation did not change the mitochondrial content in the liver, judged from the levels of COX4 and PGC-1a proteins (Fig. 2). However, the antioxidant capacity could be affected. The changes of two important mitochondrial proteins, SOD2 and SIRT3, are very similar (Fig. 2), however, significant differences were only observed in treatment, APP/PS1 $1^{\mathrm{TG}}$-E-P $)$ groups $(\mathrm{n}=6) . \quad * \mathrm{P}<0.05$, $* * \mathrm{P}<0.01, * * * \mathrm{P}<0.001$ versus control group, ${ }^{\#} \mathrm{P}<0.05$, ${ }^{\# \#} \mathrm{P}<0.01,{ }^{\# \# \#} \mathrm{P}<0.001$ versus $\mathrm{Wt}$ group. The lines above the columns indicate the significant differences between the groups (E-P vs. P; E vs. E-P)

SOD2 levels. APP/PS1 ${ }^{\mathrm{TG}}$ mice have suppressed levels of Mn-SOD compared to wild mice, suggesting elevated sensitivity to oxidative stress. Exercise training and probiotic treatment increased SOD2 protein levels, but the sum effects of these treatments neutralized each other. NRF-2, which is one of the regulators of antioxidant defence, showed a powerful increase in the probiotic supplemented exercising 
group, while probiotic treatment itself resulted in comparable levels of NRF-2 protein as found for the control group (Fig. 2).

The phosphorylation of AMPK was decreased in the liver of the exercised group, and the pAMPK/ AMPK ratio was lowest in this group (Fig. 2). Theoretically, the phosphorylation of AMPK can curb the activity of mTOR. However, in this study we found no difference in the levels of phospho $\mathrm{mTOR} / \mathrm{mTOR}$ for the wild and control APP/PS1TG mice (Fig. 2) and the pattern of pAMPK/AMPK and phospho mTOR/ mTOR showed no strong relationship. The ratio of $\mathrm{pmTOR} / \mathrm{mTOR}$ tended to decrease in the liver of the exercise trained mice, but probiotic supplementation alone resulted in significant increases in the ratio, when compared to the exercise groups. Surprisingly, the phospho $\mathrm{mTOR} / \mathrm{mTOR}$ ratio in the liver of combination treated animals, showed similar values to the control animals. In addition, the ratio of phosphorylated and total ribosomal protein S6 kinase was statistically similar in all groups and the levels of GLUT4 in the liver were not altered by the treatments. Correlated data obtained from the microbiome analyses and the immunoblot results for the liver, did not demonstrate any significant relationships.

\section{Discussion}

Alzheimer's Disease has a powerful impact on brain function. However, data suggest that $\mathrm{AD}$ also has systemic effects on the body. It is known, from $\mathrm{AD}$ models in rodents, that $\mathrm{AD}$ impairs the function of peripheral organs such as liver, kidney, and small intestine (González-Domínguez et al. 2015b; Pan et al. 2019). Metabolomic results from APP/PS1 mouse models revealed that the liver was the organ first affected during the progression of amyloid pathology, demonstrating impaired energy metabolism, amino acid metabolism, nucleic acid metabolism, as well as ketone and fatty acid metabolism (Zheng et al. 2019). In addition the systemic effects of physical exercise have also been well demonstrated (Radak et al. 2008, 2019, 2020). In the present study, we examined the effects of regular exercise, and probiotic treatment on the liver.

Liver experiences a significant drop in blood flow during acute exercise. Because of the central role of the liver in lipid, protein, and carbohydrate metabolism, the regular exercise-mediated adaptation of this organ is of particular importance (Radak et al. 2020). One of the most interesting findings of this study was that the combined effects of exercise training and probiotic supplementation significantly increased the levels of NRF-2 in the liver. NRF-2 is one of the key players of the cellular defense mechanisms against oxidative stress via the activation of antioxidant response element (ARE) genes, including SOD (Magesh et al. 2012). However, it is important to note, that the increase in NRF2 protein levels does not necessarily mean an increase of the activation of ARE, since we do not have information on keap1 expression and translocation of NRF2 (Ma and He 2012).

Besides the role of NRF-2 in the antioxidant system, it is also an important regulator of glucose/ glycogen metabolism. Increased levels of NRF-2 in the liver are associated with increased glycogen content, but decreased content in skeletal muscle (Uruno et al. 2016). In the exercise plus probiotics treated group we found enhanced levels of NRF-2, which could indicate that the joint effects of these treatments increased the glycogen stores in the liver, which could be part of an adaptive process to training. However, the levels of GLUT4 remained unchanged. The increased protein content of SOD2 could easily be the NRF-2 mediated induction of ARE. It is important to note, that the SOD2 levels in APP/PS1 transgenic mice were significantly lower than those of the wild types, suggesting a mitochondrial oxidative stress. Indeed, it has been shown that APP/PS1 transgenic animals suffer from impaired mitochondrial transport (Völgyi et al. 2018), increased mitochondrial ROS generation, increased 8-oxodG content, and SOD2 levels in the hippocampus (Bo et al. 2014). Our data suggest, that in this $\mathrm{AD}$ model the mitochondrial network, not only in the brain, but also in the liver, is under oxidative stress. Moreover, it is important to note that NRF-2 also has an anti-inflammatory role since it can suppress nuclear factor (NF) KB (Abdelsalam and Safar 2015). It is also known that exercise can curb the age-associated increase in NF-kB activity in rodents (Radák et al. 2004). Our probiotic treatment, Framelin, contained omega 3, B12 vitamin and lactobacillus, the levels of which correlated with lifespan on a caloric restricted model, with reduced inflammation (Zhang et al. 2013). Therefore, the combined effects of exercise and Framelin treatment 
could suppress the inflammatory process associated with this AD model (Duyckaerts et al. 2007).

The decreased levels of pAMPK/AMPK ratio in the exercised group suggest enhanced gluconeogenesis, which promotes generation of glucose from various sources such as tryglycerides, proteins, and lactate. Decreased pAMPK/AMPK levels and an increased $\mathrm{pmTOR} / \mathrm{mTOR}$ ratio, could mean increased levels of apoptosis in the liver (Chen et al. 2019). However, in our case, the pmTOR/mTOR ratio in the exercise trained transgenic animals was decreased, albeit not significantly, compared to the control group. This could be an interesting observation, since it has been suggested that inhibition of the mTOR pathway, by nutrient, could lead to an increased life-span (Johnson et al. 2013). On the other hand, the pmTOR/mTOR ratio of the probiotic treated transgenic animals was significantly higher than that of the exercise trained and probiotic treated groups, suggesting that the given probiotic treatment might have pro-aging effects on the liver. This is interesting, since the probiotics we used, Framelin, contained Bifidobacterium longum, Lactobacillus acidophilus lysates, besides B vitamins and omega 3 fatty acids, which could improve the antioxidant defense (Guo et al. 2017; Liakopoulos et al. 2019), while the alteration of the pmTOR/mTOR pathway, could stimulate pro-aging cellular signaling.

The ribosomal protein S6 kinase is down-stream in the mTOR signaling pathway, which encodes a number of important kinases in the induction of protein synthesis (Tavares et al. 2015). In the present study we could not detect a significant alteration of the pS6/S6 ratio. However, the combined effects of exercise and probiotics did tend to suppress the ratio $(\mathrm{p}<0.854)$.

Overall, the obtained results suggest that liver is under oxidative stress in APP/PS1 transgenic mice, due to the suppressed antioxidant defense, and exercise training has beneficial effects on the antioxidant system in this Alzheimer's model. Our data suggest that exercise and probiotics-induced changes in the microbiome do not strongly affect the mitochondrial density, and protein synthesis- related AMPK/mTOR/ S6 pathways.

Acknowledgements This study was supported by OTKA (112810) and National Excellence Program (126823), and Scientific Excellence Program TUDFO/51757/2019-ITM, at the University of Physical Education, Innovation and Technology Ministry, Hungary. Grants awarded to Z.R.
Author contributions TT, DA, MJ, SK, RM, JF, DS, MW and ZR contributed by searching the research literature and being involved in discussions of the relevant literature. ZR drafted the final version of the paper, but all contributed to the manuscript writing. All authors have read and approved the final version of the manuscript, and agree with the order of presentation of the authors. The authors acknowledge the assistance of Professor AW. Taylor in the preparation of this article.

Funding Open access funding provided by University of Physical Education.

\section{Compliance with ethical standards}

Conflict of interest The authors declare that they have no competing interests.

Open Access This article is licensed under a Creative Commons Attribution 4.0 International License, which permits use, sharing, adaptation, distribution and reproduction in any medium or format, as long as you give appropriate credit to the original author(s) and the source, provide a link to the Creative Commons licence, and indicate if changes were made. The images or other third party material in this article are included in the article's Creative Commons licence, unless indicated otherwise in a credit line to the material. If material is not included in the article's Creative Commons licence and your intended use is not permitted by statutory regulation or exceeds the permitted use, you will need to obtain permission directly from the copyright holder. To view a copy of this licence, visit http://creativecommons.org/licenses/by/4.0/.

\section{References}

Aamann L, Tandon P, Bémeur C (2019) Role of exercise in the management of hepatic encephalopathy: experience from animal and human studies. J Clin Exp Hepatol 9:131-136. https://doi.org/10.1016/j.jceh.2018.07.006

Abdelsalam RM, Safar MM (2015) Neuroprotective effects of vildagliptin in rat rotenone Parkinson's disease model: role of RAGE-NFKB and Nrf2-antioxidant signaling pathways. J Neurochem 133:700-707. https://doi.org/10.1111/jnc. 13087

Abe K (2012) Total daily physical activity and the risk of ad and cognitive decline in older adults. Neurology 79:1071. https://doi.org/10.1212/WNL.0b013e31826bd5cf

Abraham D, Feher J, Scuderi GL et al (2019) Exercise and probiotics attenuate the development of Alzheimer's disease in transgenic mice: role of microbiome. Exp Gerontol 115:122-131. https://doi.org/10.1016/j.exger.2018.12.005

Adlard PA (2005) Voluntary exercise decreases amyloid load in a transgenic model of Alzheimer's disease. J Neurosci 25:4217-4221. https://doi.org/10.1523/JNEUROSCI. 0496-05.2005

Allen JM, Mailing LJ, Niemiro GM et al (2018) Exercise alters gut microbiota composition and function in lean and obese humans. Med Sci Sports Exerc 50:747-757. https://doi.org/ 10.1249/MSS.0000000000001495 
Aziz Q, Doré J, Emmanuel A et al (2013) Gut microbiota and gastrointestinal health: current concepts and future directions. Neurogastroenterol Motil 25:4-15. https://doi.org/ 10.1111/nmo.12046

Bäuerl C, Collado MC, Diaz Cuevas A et al (2018) Shifts in gut microbiota composition in an APP/PSS1 transgenic mouse model of Alzheimer's disease during lifespan. Lett Appl Microbiol 66:464-471. https://doi.org/10.1111/lam.12882

Bell JS, Spencer JI, Yates RL et al (2019) Invited review: from nose to gut - the role of the microbiome in neurological disease. Neuropathol Appl Neurobiol 45:195-215. https:// doi.org/10.1111/nan.12520

Bo H, Kang W, Jiang N et al (2014) Exercise-induced neuroprotection of hippocampus in APP/PS1 transgenic mice via upregulation of mitochondrial 8-oxoguanine DNA glycosylase. Oxid Med Cell Longev 2014:834502. https://doi. org/10.1155/2014/834502

Bradford MM (1976) A rapid and sensitive method for the quantitation of microgram quantities of protein utilizing the principle of protein-dye binding. Anal Biochem 72:248-254

Brenner SR (2013) Blue-green algae or cyanobacteria in the intestinal micro-flora may produce neurotoxins such as Beta-N-Methylamino-l-Alanine (BMAA) which may be related to development of amyotrophic lateral sclerosis, Alzheimer's disease and Parkinson-Dementia-Complex in. Med Hypotheses 80:103. https://doi.org/10.1016/j.mehy. 2012.10.010

Chen X, Li C, Chen Y et al (2019) Aflatoxin B1 impairs leydig cells through inhibiting AMPK/mTOR-mediated autophagy flux pathway. Chemosphere 233:261-272. https://doi. org/10.1016/j.chemosphere.2019.05.273

Collins SM, Surette M, Bercik P (2012) The interplay between the intestinal microbiota and the brain. Nat Rev Microbiol 10:735-742. https://doi.org/10.1038/nrmicro2876

Cryan JF, O'Mahony SM (2011) The microbiome-gut-brain axis: from bowel to behavior. Neurogastroenterol Motil 23:187-192. https://doi.org/10.1111/j.1365-2982.2010. 01664.x

Duyckaerts C, Potier M-C, Delatour B (2007) Alzheimer disease models and human neuropathology: similarities and differences. Acta Neuropathol 115:5-38. https://doi.org/10. 1007/s00401-007-0312-8

Ghiasi R, Naderi R, Sheervalilou R, Alipour MR (2019) Swimming training by affecting the pancreatic Sirtuin 1 (SIRT1) and oxidative stress, improves insulin sensitivity in diabetic male rats. Horm Mol Biol Clin Investig. https:// doi.org/10.1515/hmbci-2019-0011

González-Domínguez R, García-Barrera T, Vitorica J, GómezAriza JL (2015a) High throughput multiorgan metabolomics in the APP/PS1 mouse model of Alzheimer's disease. Electrophoresis 36:2237-2249. https://doi.org/10. 1002/elps.201400544

González-Domínguez R, García-Barrera T, Vitorica J, GómezAriza JL (2015b) Metabolomic investigation of systemic manifestations associated with Alzheimer's disease in the APP/PS1 transgenic mouse model. Mol Biosyst 11:2429-2440. https://doi.org/10.1039/c4mb00747f

Greenhill C (2020) Gut microbiome influences exercise response. Nat Rev Endocrinol 16:68-69. https://doi.org/10. 1038/s41574-019-0309-0
Grosicki GJ, Durk RP, Bagley JR (2019) Rapid gut microbiome changes in a world-class ultramarathon runner. Physiol Rep. https://doi.org/10.14814/phy2.14313

Gubert C, Kong G, Renoir T, Hannan AJ (2020) Exercise, diet and stress as modulators of gut microbiota: implications for neurodegenerative diseases. Neurobiol Dis 134:104621. https://doi.org/10.1016/j.nbd.2019.104621

Guo Q, Li S, Xie Y et al (2017) The NAD+-dependent deacetylase, Bifidobacterium longum Sir2 in response to oxidative stress by deacetylating FOXO3a and $\mathrm{SigH}(\sigma \mathrm{H})$ in Bifidobacterium longum and HEK293T cells respectively. Free Radic Biol Med 108:929-939. https://doi.org/ 10.1016/j.freeradbiomed.2017.05.012

Heijtz RD, Wang S, Anuar F et al (2011) Normal gut microbiota modulates brain development and behavior. Proc Natl Acad Sci USA 108:3047-3052. https://doi.org/10.1073/ pnas. 1010529108

Hill JM, Bhattacharjee S, Pogue AI, Lukiw WJ (2014) The gastrointestinal tract microbiome and potential link to Alzheimer's disease. Front Neurol. https://doi.org/10. 3389/fneur.2014.00043

Hornig M (2013) The role of microbes and autoimmunity in the pathogenesis of neuropsychiatric illness. Curr Opin Rheumatol 25:488-795. https://doi.org/10.1097/BOR. 0b013e32836208de

Hu X, Wang T, Jin F (2016) Alzheimer's disease and gut microbiota. Sci China Life Sci 59:1006-1023. https://doi. org/10.1007/s11427-016-5083-9

Huttenhower C, Gevers D, Knight R et al (2012) Structure, function and diversity of the healthy human microbiome. Nature 486:207-214. https://doi.org/10.1038/nature11234

Johnson SC, Rabinovitch PS, Kaeberlein M (2013) MTOR is a key modulator of ageing and age-related disease. Nature 493:338-345. https://doi.org/10.1038/nature11861

Kim B-K, Shin M-S, Kim C-J et al (2014) Treadmill exercise improves short-term memory by enhancing neurogenesis in amyloid beta-induced Alzheimer disease rats. J Exerc Rehabil 10:2-8. https://doi.org/10.12965/jer.140086

Kim B-S, Jeon Y-S, Chun J (2013) Current status and future promise of the human microbiome. Pediatr Gastroenterol Hepatol Nutr 16:71. https://doi.org/10.5223/pghn.2013.16. 2.71

Liakopoulos V, Roumeliotis S, Bozikas A et al (2019) Antioxidant supplementation in renal replacement therapy patients: is there evidence? Oxid Med Cell Longev 2019:1-23. https://doi.org/10.1155/2019/9109473

Liu L, Li P, Liu Y, Zhang Y (2019) Efficacy of probiotics and synbiotics in patients with nonalcoholic fatty liver disease: a meta-analysis. Dig Dis Sci 64:3402-3412. https://doi. org/10.1007/s10620-019-05699-z

Ma Q, He X (2012) Molecular basis of electrophilic and oxidative defense: promises and perils of Nrf2. Pharmacol Rev 64:1055-1081. https://doi.org/10.1124/pr.110.004333

Magesh S, Chen Y, Hu L (2012) Small molecule modulators of keap1-Nrf2-ARE pathway as potential preventive and therapeutic agents. Med Res Rev 32:687-726. https://doi. org/10.1002/med.21257

Mahizir D, Briffa JF, Wood JL et al (2020) Exercise improves metabolic function and alters the microbiome in rats with gestational diabetes. FASEB J 34:1728-1744. https://doi. org/10.1096/fj.201901424R 
Mancuso C, Santangelo R (2018) Alzheimer's disease and gut microbiota modifications: the long way between preclinical studies and clinical evidence. Pharmacol Res 129:329-336. https://doi.org/10.1016/j.phrs.2017.12.009

Mitew S, Kirkcaldie MTK, Dickson TC, Vickers JC (2013) Altered synapses and gliotransmission in alzheimer's disease and AD model mice. Neurobiol Aging 34:2341-2351. https://doi.org/10.1016/j.neurobiolaging.2013.04.010

Pan Y, Omori K, Ali I et al (2019) Increased expression of renal drug transporters in a mouse model of familial Alzheimer's disease. J Pharm Sci 108:2484-2489. https://doi.org/10. 1016/j.xphs.2019.02.016

Radak Z, Chung HY, Goto S (2008) Systemic adaptation to oxidative challenge induced by regular exercise. Free Radic Biol Med 44:153-159. https://doi.org/10.1016/j. freeradbiomed.2007.01.029

Radák Z, Chung HY, Naito H et al (2004) Age-associated increase in oxidative stress and nuclear factor kappaB activation are attenuated in rat liver by regular exercise. FASEB J 18:749-750. https://doi.org/10.1096/fj.030509fje

Radak Z, Hart N, Sarga L et al (2010) Exercise plays a preventive role against Alzheimer's disease. J Alzheimer's Dis 20:777-783. https://doi.org/10.3233/JAD-2010091531

Radak Z, Suzuki K, Posa A et al (2020) The systemic role of SIRT1 in exercise mediated adaptation. Redox Biol. https://doi.org/10.1016/j.redox.2020.101467

Radak Z, Torma F, Berkes I et al (2019) Exercise effects on physiological function during aging. Free Radic Biol Med 132:33-41. https://doi.org/10.1016/j.freeradbiomed.2018. 10.444

Sato Y, Qiu J, Miura T et al (2019) Effects of long-term exercise on liver cyst in polycystic liver disease model rats. Med Sci Sport $\quad$ Exerc. https://doi.org/10.1249/mss. 0000000000002251

Saulnier DM, Ringel Y, Heyman MB et al (2013) The intestinal microbiome, probiotics and prebiotics in neurogastroenterology. Gut Microbes 4:17-27. https://doi.org/10.4161/ gmic. 22973

Singhal R, Shah YM (2020) Oxygen battle in the gut: hypoxia and hypoxia-inducible factors in metabolic and inflammatory responses in the intestine. J Biol Chem. https://doi. org/10.1074/jbc.rev120.011188

Sohail MU, Yassine HM, Sohail A, Al Thani AA (2019) Impact of physical exercise on gut microbiome, inflammation, and the pathobiology of metabolic disorders. Rev Diabet Stud 15:35-48. https://doi.org/10.1900/RDS.2019.15.35
Szablewski L (2018) Human gut microbiota in health and Alzheimer's disease. J Alzheimer's Dis 62:549-560. https:// doi.org/10.3233/JAD-170908

Tavares MR, Pavan ICB, Amaral CL et al (2015) The S6K protein family in health and disease. Life Sci 131:1-10. https://doi.org/10.1016/j.lfs.2015.03.001

Uruno A, Yagishita Y, Katsuoka F et al (2016) Nrf2-mediated regulation of skeletal muscle glycogen metabolism. Mol Cell Biol 36:1655-1672. https://doi.org/10.1128/mcb. 01095-15

Vogt NM, Kerby RL, Dill-McFarland KA et al (2017) Gut microbiome alterations in Alzheimer's disease. Sci Rep. https://doi.org/10.1038/s41598-017-13601-y

Völgyi K, Badics K, Sialana FJ et al (2018) Early presymptomatic changes in the proteome of mitochondria-associated membrane in the APP/PS1 mouse model of Alzheimer's disease. Mol Neurobiol 55:7839-7857. https://doi.org/10.1007/s12035-018-0955-6

Wang J, Gu BJ, Masters CL, Wang Y-J (2017) A systemic view of Alzheimer disease: insights from amyloid- $\beta$ metabolism beyond the brain. Nat Rev Neurol 13:612-623. https://doi. org/10.1038/nrneurol.2017.111

Xu R, Wang Q (2016) Towards understanding brain-gut-microbiome connections in Alzheimer's disease. BMC Syst Biol 10:63. https://doi.org/10.1186/s12918-016-0307-y

Zhang C, Li S, Yang L et al (2013) Structural modulation of gut microbiota in life-long calorie-restricted mice. Nat Commun. https://doi.org/10.1038/ncomms3163

Zhang L, Wang Y, Xiayu X et al (2017) Altered gut microbiota in a mouse model of Alzheimer's disease. J Alzheimer's Dis 60:1241-1257. https://doi.org/10.3233/JAD-170020

Zhang X, Cao L, Ji B et al (2020) Endurance training but not high-intensity interval training reduces liver carcinogenesis in mice with hepatocellular carcinogen diethylnitrosamine. Exp Gerontol. https://doi.org/10.1016/j.exger. 2020.110853

Zheng H, Cai A, Shu Q et al (2019) Tissue-specific metabolomics analysis identifies the liver as a major organ of metabolic disorders in amyloid precursor protein/presenilin 1 mice of Alzheimer's disease. J Proteome Res 18:1218-1227. https://doi.org/10.1021/acs.jproteome. $8 \mathrm{~b} 00847$

Publisher's Note Springer Nature remains neutral with regard to jurisdictional claims in published maps and institutional affiliations. 